[2] O'Brien W, Fissel BM, Maeda Y, Yan J, Ge X, Gravallese EM, Aliprantis AO, Charles JF. RANK-Independent Osteoclast Formation and Bone Erosion in Inflammatory Arthritis. Arthritis Rheumatol. 2016 Dec;68(12):28892900.

Disclosure of Interest: None declared

DOI: 10.1136/annrheumdis-2018-eular.5383

\section{AB0125 ANTI-DENGUE IGG ANTIBODY POSITIVITY AND RISK OF DEVELOPING RHEUMATOID ARTHRITIS: EVIDENCE FROM THE MALAYSIAN EPIDEMIOLOGICAL INVESTIGATION OF RHEUMATOID ARTHRITIS (MYEIRA) CASE-CONTROL STUDY}

L.K. $\operatorname{Tan}^{1,2}$, N.A. Ahmad Fauzi ${ }^{1}$, W. Sulaiman' ${ }^{2}$, O. Ali ${ }^{2}$, I.S. Lau ${ }^{3}$, H. Hussein ${ }^{4}$, N. S. Sharil ${ }^{4}$, S.C. Gun ${ }^{5}$, E. Mageswaren ${ }^{4}$, M.-S. Mohd-Said ${ }^{6}$, A. Mohd-Mokhtar ${ }^{7}$, A. Rosman ${ }^{3}$, M. Othman ${ }^{8}$, C. Bengtsson ${ }^{9}$, L. Alfredsson ${ }^{9}$, L. Klareskog ${ }^{10}$, S. Murad ${ }^{11}$, L. Padyukov ${ }^{10}$, C.L. Too ${ }^{1,10}{ }^{1}$ Allergy and Immunology Research Center, Institute for Medical Research, Ministry of Health Malaysia, Kuala Lumpur, ${ }^{2}$ Faculty of Medicine, University Kuala Lumpur Royal College of Medicine Perak, Ipoh, Perak; ${ }^{3}$ Department of Medicine, Selayang Hospital, Selangor, ${ }^{4}$ Department of Medicine, Putrajaya Hospital, Putrajaya; ${ }^{5}$ Department of Medicine, Hospital Tunku Ja'afar, Seremban, Negeri Sembilan; ${ }^{6}$ Faculty of Medicine, Universiti Kebangsaan Malaysia Medical Center, Kuala Lumpur, ${ }^{7}$ Department of Medicine, Tengku Ampuan Afzan Hospital, Kuantan, Pahang; ${ }^{8}$ Department of Medicine, Hospital Raja Perempuan Bainun, Ipoh, Perak, Malaysia; ${ }^{9}$ Institute of Environmental Medicine, Karolinska Institutet, ${ }^{10}$ Department of Medicine, Rheumatology Unit, Karolinska Institutet and Karolinska University Hospital, Stockholm, Sweden; ${ }^{11}$ Ministry of Health, Level 12th, Block E7, Parcel E, Federal Government Adminstrative Center, Putrajaya, Malaysia

Background: Arthralgia is one of the common symptoms seen in RA and in mosquito-borne viral diseases (dengue and chikungunya infections). Studies have reported that both dengue and chikungunya infections are associated with longterm persistent rheumatic symptoms including joints, muscle and bone pain.

Objectives: We investigated the association between anti-dengue $\operatorname{lgG}$ antibody positivity and risk of developing anti-citrullinated peptide antibody (ACPA)-positive and ACPA-negative RA in the multi-ethnic Malaysian population.

Methods: A total of 1147 early RA cases (515 Malay, 254 Chinese and 378 Indians) and 1519 age, sex and residential area matched population-based controls (1,023 Malay, 208 Chinese, and 288 Indians) were included in this study. Antidengue IgG antibody was determined by ELISA method. The presence of antidengue IgG antibody and risk of developing ACPA-positive/ACPA-negative RA were estimated by calculating the odds ratio (OR) with $95 \%$ confidence interval $(95 \% \mathrm{Cl})$.

Results: Our data demonstrated that $79.1 \%(n=1,003)$ and $77.1 \%(n=1,255)$ RA and control subjects were positive for anti-dengue $\lg G$ antibody, respectively. Data analysis revealed that the Chinese RA patients has highest frequency of anti-dengue IgG antibody (86.6\%) followed by the Indian (80.4\%) and Malay (74.4\%) RA patients while $83.7 \%, 87.5 \%$ and $73 \%$ Chinese, Indian and Malay healthy controls were positive for this antibody, respectively. The anti-dengue IgG antibody positivity was significantly associated with decreased risk of RA in the Indian population (OR $0.59,95 \% \mathrm{Cl}: 0.38-0.91, \mathrm{p}=0.02$ ) and particularly for the ACPA-positive subset of RA (OR $0.60,95 \% \mathrm{Cl} 0.37-0.96, \mathrm{p}=0.03$ ). Interestingly, we observed a non-significant increased risk for ACPA-positive RA in the Chinese (OR $1.49,95 \% \mathrm{Cl} 0.81-2.72$ ) and Malay populations (OR 1.06, 95\% Cl: $0.79-$ 1.41) with anti-dengue $\operatorname{lgG}$ antibody. No association was observed between ACPA-negative RA and the antibody positivity.

Conclusions: Our study describes the association between anti-dengue $\lg G$ antibody occurrence and ACPA-positive RA, but not ACPA-negative RA in an ethnicity-dependent manner. Future research is needed to explore the biological mechanisms behind these findings.

\section{REFERENCES:}

[1] Mohd Zim MA, et al. Chikungunya infection in Malaysia: Comparison with dengue infection in adults and predictors of persistent arthralgia. Journal of Clinical Virology 2013;56(2013):141-145.

[2] Gissel Garci' et al. Long-term persistence of clinical symptoms in dengueinfected persons and its association with immunological disorders. International Journal of Infectious Diseases 2011:15(2011):e38-e43.

Disclosure of Interest: None declared

DOI: 10.1136/annrheumdis-2018-eular.6190

\section{$\mathrm{AB} 0126$ \\ LOW PREVALENCE OF ANTIBODIES AGAINST MALONDIALDEHYDE-ACETALDEHYDE ADDUCTS IN SPANISH PATIENTS WITH RHEUMATOID ARTHRITIS}

L. Rodriguez-Martinez, E. Perez-Pampin, A. Mera-Varela, C. Conde, A. Gonzalez. Experimental and Observational Rheumatology, Instituto Investigacion SanitariaH. Clinico Universitario de Santiago, Santiago de Compostela, Spain

Background: Patients with rheumatoid arthritis (RA) present increased oxidative stress that leads to lipid peroxidation and the formation of malondialdehyde (MDA) and acetaldehyde (AA). These two compounds under oxidative stress form malondialdehyde-acetaldehyde (MAA) adducts with proteins, which are highly immunogenic. Recently, Thiele et al. ${ }^{1}$ described the presence of antibodies against human albumin MAA adducts in patients with established RA from the Veterans Affairs Rheumatoid Arthritis (VARA) registry. Of particular relevance was the reported presence of IgG anti-MAA antibodies in $92 \%$ of the patients, including $88 \%$ of the anti-CCP negative patients. These results suggest MAA adducts could contribute to the pathogenesis of RA and the anti-MAA antibodies could drastically reduce the number of patients with seronegative RA.

Objectives: To replicate the association of anti-MAA antibodies with RA and explore their value as biomarkers.

Methods: Sera from 515 Spanish patients with established RA that fulfilled the 1987 ACR classification criteria and from 274 healthy controls were included. Available information included history of smoking, anti-CCP status, and genotype of HLA-DRB1 and PTPN22 rs2476601. Human serum albumin MAA adducts and hexyl-MAA standard were chemically synthesised. Anti-MAA antibodies against the albumin MAA adducts were determined by indirect ELISA using isotype-specific secondary antibodies for $\lg G$, $\lg M$ and $\lg A$.

Results: Anti-MAA antibodies were detected in a small fraction of the RA patients, who had slightly increased antibody titers compared to healthy controls, $6.4 \%$ were positive for $\lg$ G, $15.7 \%$ for $\lg M$ and $8.0 \%$ for $\lg A$. The low prevalence of anti-MAA antibodies persisted in spite of multiple variations in the ELISA protocols including the use of different albumin sources, albumin MAA adducts produced in two different laboratories, and various secondary antibodies. IgM antiMAA antibody titers were increased in smokers compared to non-smokers. Moreover, the presence of $\lg M$ and of $\operatorname{IgA}$ anti-MAA antibodies were associated with anti-CCP and RF positivity.

Conclusions: Anti-MAA antibodies were detected in a small fraction of the Spanish RA patients, but their low sensitivity questions the value of these antibodies as biomarkers of RA. Due to the contradictory findings, additional studies should be performed that will need to address also the role of MAA adducts on RA pathogenesis.

\section{REFERENCE:}

[1] Thiele GM, et al. Arthritis Rheumatol 2015;67(3):645-55.

Acknowledgements: Supported by grants PI14/01651 and RD16/0012/0014 of the Instituto de Salud Carlos III (Spain) that are partially financed by the ERDF Disclosure of Interest: None declared

DOI: 10.1136/annrheumdis-2018-eular.4583

\section{$\mathrm{AB} 0127$ \\ ANTI-INFLAMMATORY AND PRO-APOPTOSIS EFFECTS OF 18BETA-GLYCYRRHETINIC ACID IN IN VIVO AND IN} VITRO MODELS OF RHEUMATOID ARTHRITIS

M. Wang ${ }^{1,2}$, R. Huang ${ }^{1}$, on behalf of Runyue Huang Group. ${ }^{1}$ Rheumatology, Guangdong Provincial Hospital of Chinese Medicine, Guangzhou, China; ${ }^{2}$ Center for Molecular Medicine, University Medical Center Utrecht, Utrecht, Netherlands

Background: Rheumatoid arthritis (RA) is one of the most common autoimmune diseases and it affects $0.5 \%-2.0 \%$ of the human population worldwide. ${ }^{1}$ Though disease modifying anti-rheumatic drugs (DMARDs) can improve the clinical condition of patients with RA, toxicities of these drugs will be accumulated with longterm use and the unwanted side effects still cannot be avoided. $18 \beta$-glycyrrhetinic acid (18 $\beta-\mathrm{GA})$, an active component of licorice, exhibits potential anti-cancer, antiinflammatory, anti-allergic, and anti-microbial activities. ${ }^{2}$ Moreover, $18 \beta-G A$ has been elucidated to attenuate hepatotoxicity or nephrotoxicity caused by chemical drugs, included methotrexate(MTX)[. ${ }^{2}$ These evidences suggested $18 \beta$-GA may become a candidate for low toxicity RA therapy as the mechanism was revealed. Objectives: The aim of this study is to investigate the underline mechanism of $18 \beta-$ GA on anti-inflammation and anti-proliferation in in vivo and in vitro models of RA.

Methods: CIA rats were treated with $18 \beta-\mathrm{GA}$, methotrexate, celecoxib and three combination therapies for 30 days. Paw swelling volume, thromboxane synthase (TxAS), proliferating cell nuclear antigenprotein (PCNA), interleukin (IL) - 1及, IL-6, and thromboxane B2 (TxB2) were detected to assess the anti-inflammation and 